\section{Re: Technical issues in ultrasound-guided ethanol ablation for thyroid lesions}

\author{
Woojin Cho' ${ }^{1}$ Jung Suk Sim², So Lyung Jung ${ }^{3}$ \\ Departments of ${ }^{1}$ Otolaryngology-Head and Neck Surgery and ${ }^{2}$ Radiology, Withsim Clinic, \\ Seongnam; ${ }^{3}$ Department of Radiology, Yeouido St. Mary's Hospital, College of Medicine, The \\ Catholic University of Korea, Seoul, Korea
}

We greatly appreciate your detailed and constructive comments. In our study, we defined a "low dose" as less than $5 \mathrm{~mL}$ [1]. However, we did not propose a precise amount of ethanol according to the nodule volume or the cystic nature of the thyroid nodule. This might be a limitation of our retrospective study. Further research is necessary. Although the exact dosage of ethanol has not been established yet, the concept of single-session low-dose ethanol ablation (EA) might be important in terms of the basic principle for drug injection, which is to obtain the maximum effect with the minimum amount. Using a small amount of ethanol has the advantages of being easy to handle during the procedure and minimizing the risk of procedure-related complications, including ethanol leakage and patient discomfort.

As you pointed out, Park et al. [2] reported a higher therapeutic success rate in a retention group than in an aspiration group, especially in predominantly cystic nodules. However, the efficacy did not show statistical significance in either the volume reduction rate $(P=0.761)$ or therapeutic success $(P=0.070)$ [2]. In addition, Baek et al. [3] reported high effectiveness despite using an aspiration method after 2 minutes of ethanol retention, and Kim et al. [4] reported that the two techniques (retention only and aspiration after injection) showed similar therapeutic success rates (96.7\% vs. $93.3 \%$ ). Whether there is a statistically significant difference between the two techniques in predominantly cystic nodules also requires further investigation.

We agree that our study includes cases with short-term follow-up, making it necessary to conduct a subsequent study with long-term results. Including your opinions on technical issues, we hope that these discussions and our study could provide basic data for future studies and the standardization of EA procedures.

ORCID: Woojin Cho: https://orcid.org/0000-0002-9059-648X; Jung Suk Sim: https://orcid.org/0000-0001-6803-3544; So Lyung Jung: https://orcid.org/0000-0002-3267-8399

\section{Conflict of Interest}

No potential conflict of interest relevant to this article was reported.

\section{References}

1. Cho W, Sim JS, Jung SL. Ultrasound-guided ethanol ablation for cystic thyroid nodules: effectiveness of small amounts of ethanol in a single session. Ultrasonography 2021;40:417-427.

2. Park HS, Yim Y, Baek JH, Choi YJ, Shong YK, Lee JH. Ethanol ablation as a treatment strategy for benign cystic thyroid nodules: a comparison of the ethanol retention and aspiration techniques.

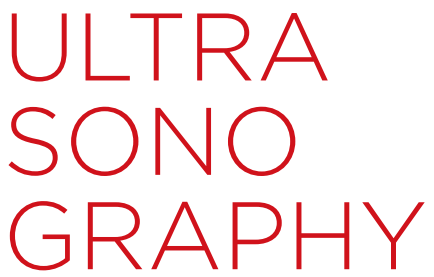

\section{LETTER}

https://doi.org/10.14366/usg.21078 pISSN: 2288-5919 • elSSN: 2288-5943 Ultrasonography 2021;40:623-624

Received: April 5, 2021

Revised: April 5, 2021

Accepted: April 13, 2021

Correspondence to: So Lyung Jung, MD, PhD, Department of Radiology, Yeouido St. Mary's Hospital, College of Medicine, The Catholic University of Korea, 10 63ro, Yeongdeungpo-gu, Seoul 07345, Korea

Tel. +82-2-3779-1019

Fax. +82-2-783-5288

E-mail: sljung1@catholic.ac.kr

This is an Open Access article distributed under the terms of the Creative Commons Attribution NonCommercial License (http://creativecommons.org/ licenses/by-nc/4.0/) which permits unrestricted noncommercial use, distribution, and reproduction in any medium, provided the original work is properly cited.

Copyright (C) 2021 Korean Society of Ultrasound in Medicine (KSUM)

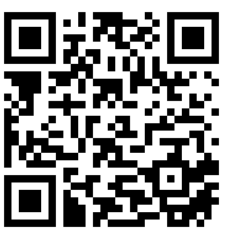

How to cite this article:

Cho W, Sim JS, Jun SL. Re: Technical issues in ultrasound-guided ethanol ablation for thyroid lesions. Ultrasonography. 2021 Oct;40(4):623 624 
Ultrasonography 2019;38:166-171.

3. Baek JH, Ha EJ, Choi YJ, Sung JY, Kim JK, Shong YK. Radiofrequency versus ethanol ablation for treating predominantly cystic thyroid nodules: a randomized clinical trial. Korean J Radiol 2015;16:13321340.
4. Kim DW, Rho MH, Kim HJ, Kwon JS, Sung YS, Lee SW. Percutaneous ethanol injection for benign cystic thyroid nodules: is aspiration of ethanol-mixed fluid advantageous? AJNR Am J Neuroradiol 2005;26:2122-2127. 